\title{
Null expectation of spatial correlograms under a stochastic process of genetic divergence with small sample sizes
}

\author{
Mariana Pires de Campos Telles ${ }^{1,3}$ and José Alexandre Felizola Diniz-Filho ${ }^{2}$
}

\begin{abstract}
An Ornstein-Uhlenbeck process was used to simulate the exponential relationship between genetic divergence and geographic distances, as predicted by stochastic processes of population differentiation, such as isolation-by-distance, stepping-stone or coalescence models. These simulations were based only on the spatial coordinates of the local populations that defined a spatial unweighted pair-group method using arithmetic averages (UPGMA) link among them. The simulated gene frequency surfaces were then analyzed using spatial autocorrelation procedures and Nei's genetic distances, constructed with different numbers of variables (gene frequencies). Stochastic divergence in space produced strong spatial patterns at univariate and mutivariate levels. Using a relatively small number of local populations, the correlogram profiles varied considerably, with Manhattan distances greater than those defined by other simulation studies. This method allows one to establish a range of correlogram profiles under the same stochastic process of spatial divergence, thereby avoiding the use of unnecessary explanations of genetic divergence based on other microevolutionary processes.
\end{abstract}

\section{INTRODUCTION}

Patterns and processes of genetic divergence among local populations have recently been investigated using spatial correlograms to describe autocorrelation of gene frequencies for increasing classes of spatial distance (Sokal and Jacquez, 1991). Simulations have shown that this technique is a powerful tool for studying the microevolutionary processes of genetic divergence (Sokal and Wartenberg, 1981; Sokal et al., 1989, 1997; Epperson, 1995a,b).

One of the random processes most widely used to describe the present genetic divergence among local populations is isolation-by-distance (Wright, 1943) and its discontinuous version, the stepping-stone model (Kimura and Weiss, 1964). The basic isolation-by-distance model is usually modeled in a unidimensional distribution space through the Morton-Malecot equation

$$
\phi(\mathrm{d})=a c^{-b d}
$$

where $\phi(d)$ is the "kinship" between populations located at a geographic distance $d$, and $a$ and $b$ are constants that can be interpreted as a function of the demographic and genetic characteristics of the populations (Wijsman and Cavalli-Sforza, 1984). In both models, a negative exponential relationship between genetic similarity and spatial distance is generated by drift in local populations and is constrained by migration effects at short distances. This rela- tionship also holds for coalescence models, in which the main determinant of divergence is genetic drift within local populations, that accumulates variance through time and not through spatially structured gene flow (Nielsen et al., 1998; Avise, 2000).

Sokal and Wartenberg (1983) showed that isolationby-distance correlograms have similar profiles, with an exponential decrease between autocorrelation and geographic distances, despite the low correlation among surfaces. Testing the similarity of correlograms and comparison of the results with correlations among gene frequencies are then analogous to the Lewontin-Krakauer test of neutrality based on the homogeneity of the $\mathrm{F}_{\mathrm{ST}}$ statistics (Kimura, 1983; Barbujani, 1987). Sokal and Wartenberg (1983) and Sokal (1986) proposed that the same stochastic spatial process could generate correlograms with Manhattan distances of less than 0.1 or 0.2 (produced using uncorrelated gene frequencies). However, a critical aspect of this proposal is that if the sample size (number of local populations) used to construct the correlograms is small, their profiles can vary considerably, even if they were generated by the same stochastic process of population divergence.

In this paper, we used an Ornstein-Uhlenbenck $(\mathrm{O}-\mathrm{U})$ stochastic process to simulate exponential relationships between genetic divergence and geographic distance, in a manner analogous to isolation-by-distance, stepping-stone or coalescence models. For a specified sample size and

${ }^{1}$ Programa de Pós-graduação em Agronomia, Escola de Agronomia, Universidade Federal de Goiás, Caixa Postal 131, 74001-970 Goiânia, GO, Brasil. E-mail: telles@icb1.ufg.br

${ }^{2}$ Departamento de Biologia Geral, ICB, Universidade Federal de Goiás, Caixa Postal 131, 74001-970 Goiânia, GO, Brasil. ${ }^{3}$ Departamento de Zootecnia, Universidade Católica de Goiás, Av. Universitária, 1440, Caixa Postal 86, $74605-010$ Goiânia, GO, Brasil. Send correspondence to J.A.F.D.-F.E-mail: diniz@icb1.ufg.br 
spatial distribution of local populations, this relatively simple and general method allows definition of the null expectation of variation for correlograms under a simple stochastic process of spatial divergence among local populations.

\section{MATERIAL AND METHODS}

We simulated gene frequencies for 13 local populations distributed geographically as shown in Figure 1. These localities were used in an isozyme study of Eugenia dysenterica DC (Myrtaceae) population genetics in a region of the Brazilian "cerrado" (Telles, 2000), and served to illustrate the procedure developed here. Simulations were performed with the PDAP software (phenotypic diversity analysis program - Díaz-Uriarte and Garland, 1996) based on an unweighted pair-group method using arithmetic averages (UPGMA) clustering of geographic distances (Sneath and Sokal, 1973), designed to represent the pairwise distances among local populations in a tree format. The cophenetic correlation of clustering was very high $(\mathrm{r}=0.96)$, which ensured that running simulations with PDAP across this tree simulated a spatial diffusion process. Thus, the branch lengths of UPGMA based on geographic distances must be interpreted as a parameter related to the expected amount of gene flow among local populations. On the other hand, if one wishes to simulate a spatially structured coalescence model (Avise, 2000), these branch lengths are a direct estimate of the divergence time between local populations.

An O-U stochastic process (Felsenstein, 1988; Martins, 1995; Hansen and Martins, 1996) was then used to generate 500 distributions of gene frequencies $p$ maintaining an exponential relationship between genetic divergence and geographic distances represented in UPGMA clustering, as expected by the Malecót-Morton equation for isolation-by-distance and by other stochastic processes of

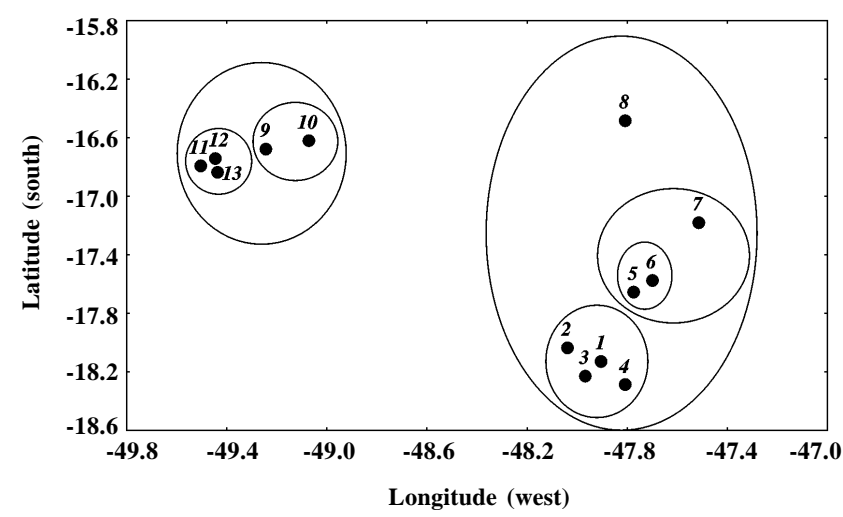

Figure 1 - Schematic map of the spatial distribution of the 13 local populations used in the simulations. The circles indicate the main spatial hierarchy defined by unweigthed pair-group method using arithmetic averages (UPGMA) clustering of geographic distances. population differentiation. In the O-U process, the evolutionary changes were constrained by a constant force toward a central point (the adaptive peak of $p$ ), and the pairwise covariance among local populations $\left(\mathrm{V}_{\mathrm{B}}\right.$, equivalent to $\phi(d))$ was related to distance (d) by the exponential relationship

$$
\mathrm{V}_{\mathrm{B}}=\sigma^{2} / 2 \alpha\left(1-e^{-2 \alpha \mathrm{d}}\right)+\varepsilon
$$

where $\sigma^{2}$ is the variance of evolutionary change under a stochastic process, and $\alpha$ is the restraining force. The variance of evolutionary changes per unit of time (or space) in the simulations indicates the range of deviations of $p$ from its "ancestral" value, and is a function of the variance of $p$ (see below) and of the maximum distance between pairs of local populations $\left(\mathrm{d}_{\max }\right)$. Following Díaz-Uriarte and Garland (1996), the restraining force $\alpha$ was set to $2 / d_{\max }$, in order to produce a moderate exponential relationship between $V_{B}$ and geographic distance. There is an equivalence between the previously defined Malecót-Morton equation and the $\mathrm{O}-\mathrm{U}$ process, with the constants $a$ and $b$ being expressed in terms of $\sigma^{2}, \alpha$ and $e$.

Since the O-U process "forgets" past events (in this case, long-range spatial patterns), it reduces the level of "spatial inertia" in the data. At each instant of divergence in time or space, the stochastic variation in $p$ can be pushed to the adaptive peak if the value of gene frequencies becomes too high or too low, which explains the exponential decrease of genetic divergence when distantly related populations are compared (Felsenstein, 1988). The assumption of a constant population size through time, present in most models of population differentiation, is approximated in the $\mathrm{O}-\mathrm{U}$ model used here by the constant variance in evolutionary changes throughout the process.

All simulations started with an initial gene frequency (the adaptive peak) of $0.5 \pm 0.04$, so that most values of gene frequencies would fall between zero and 1.0 (values of $p$ assume a normal distribution). However, since PDAP was originally developed to generate variation in continuous traits, we also used the boundary option of the program to constrain the variation between zero and 1.0 (the "replace" algorithm; Díaz-Uriarte and Garland, 1996).

Each gene frequency vector simulated represented surfaces of variation in geographic space (sensu Sokal and Oden, 1978a,b), and was analyzed and interpreted using standard procedures of spatial autocorrelation (Sokal and Oden, 1978a,b; Sokal and Jacquez, 1991). Moran's I coefficients were estimated in four geographic distance classes in order to generate the spatial correlograms. A Pearson correlation coefficient was calculated between Moran's I values and the upper limit of the distance class in order to evaluate the linearity of the decrease of each correlogram.

To provide microevolutionary inferences (Sokal and Jacquez, 1991), the correlograms were then compared using pairwise Manhattan distances, which were also compared with pairwise Pearson correlations among original 
gene frequency surfaces. Based on previous studies (Sokal and Wartenberg, 1983; Sokal and Jacquez, 1991), similar correlograms were expected to appear, even if they originated from uncorrelated gene frequency surfaces.

We also analyzed multivariate patterns of spatial autocorrelation under this $\mathrm{O}-\mathrm{U}$ stochastic process by randomly sampling the gene frequencies to estimate Nei's (1972) genetic distances among local populations. A total of 100 genetic distance matrices were constructed using 10, 20 and 30 gene frequencies. Each matrix was compared with the geographic distances by the Mantel test, which was used to establish the statistical significance of the matrix correlation using 1,000 permutations (Sokal et al., 1986; Manly, 1991).

\section{RESULTS}

The correlograms obtained from the gene frequency surfaces (Figure 2) usually showed a monotonic decrease in Moran's I coefficient with geographic distance, with very high negative correlations among them (Figure 3 ). The average correlogram showed a continuous decrease in Moran's I coefficients with distance, suggesting a clinal pattern in space (Sokal and Oden, 1978a,b). Other simulations (Sokal and Wartenberg, 1983; Sokal and Jacquez, 1991; Sokal et al., 1997) produced a more stabilizing pattern in Moran's I coefficient in the last distance classes. However, in our study, the variance of the coefficients decreased strongly in this class in such a way that the profiles were then compatible with those obtained in these previous studies.

The values of the Manhattan distances between correlograms were widely distributed, ranging from 0 to 1.2 , with a modal value close to 0.2 (Figure 4). Plotting the Manhattan distances against the correlation between surfaces indicated, as expected, that dissimilar surfaces (with low correlations) can produce similar correlograms and these formed a triangular envelope in bivariate space (Figure 5).

The analysis of Nei's genetic distances using the Mantel test (Figure 6) also indicated a strong correlation between multivariate genetic divergence and geographic space under this stochastic process, although the magnitude of this correlation depended on the number of gene frequencies used to construct each matrix. The average matrix correlation (standardized Mantel test; Smouse et al., 1986) increased when the number of gene frequencies used to establish Nei's genetic distances was large, whereas the variance decreased with an increase in this number.

\section{DISCUSSION}

The correlograms obtained after simulating the variation in gene frequencies across local populations were usually highly significant, indicating that stochastic processes generated by an $\mathrm{O}-\mathrm{U}$ model produced strong spatial pat-

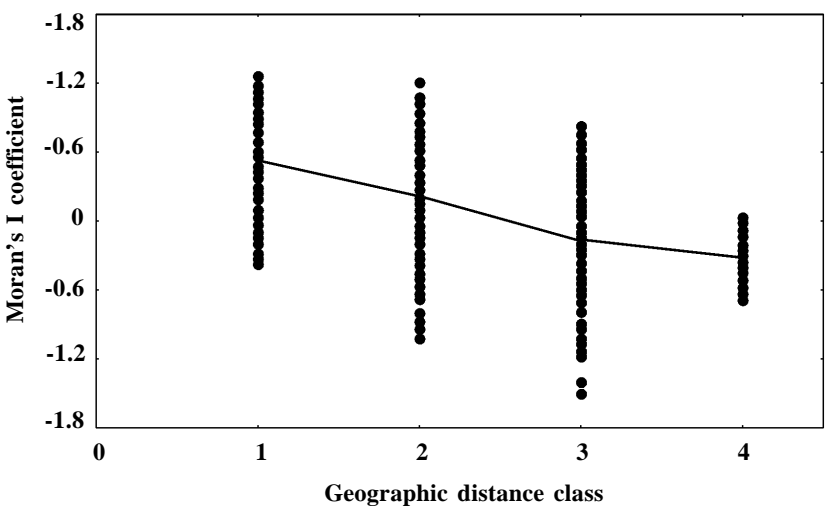

Figure 2 - Spatial correlograms obtained with simulated data. The average correlogram is shown by the solid line. See Figure 3 to examine the linear decrease in most of these correlograms.

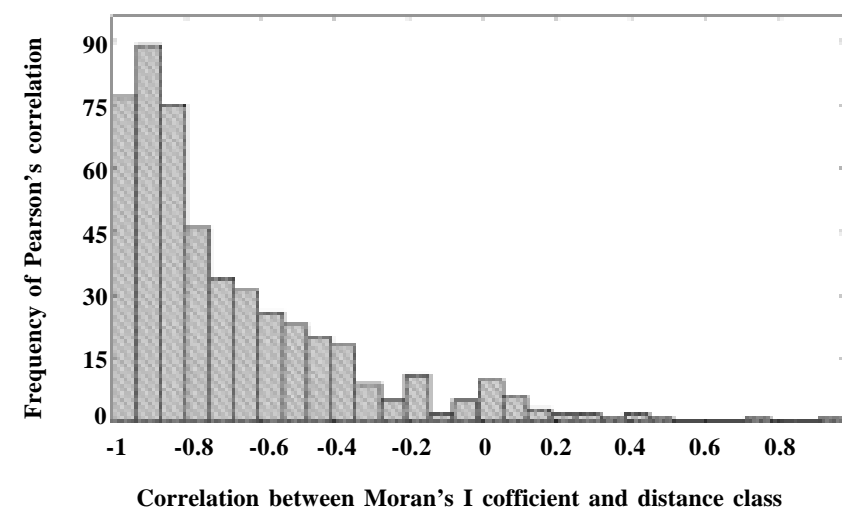

Figure 3 - Frequency distribution of correlations relative to Pearson's correlation between Moran's I coefficient and distance class. Note the high degree of linearity of the correlograms shown in Figure 2.

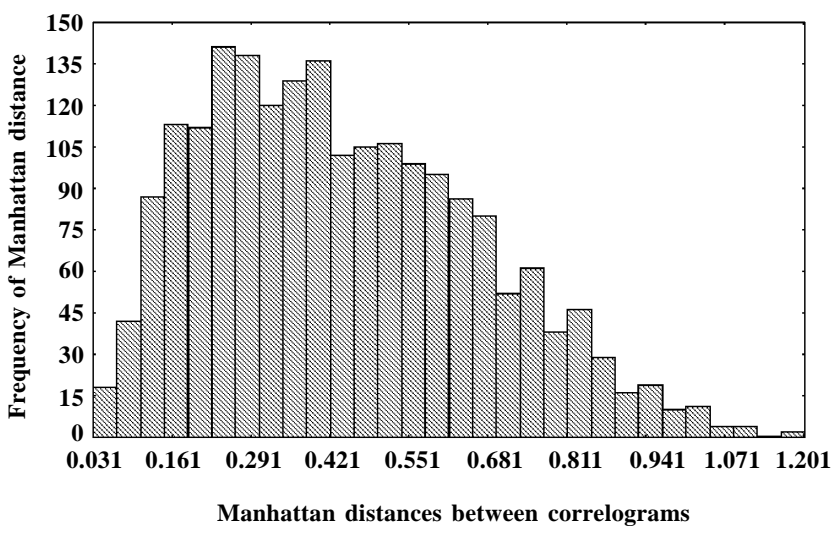

Figure 4 - Frequency distribution of pairwise Manhattan distances between correlograms generated using the Ornstein-Uhlenbeck stochastic spatial process with the same parameters. 


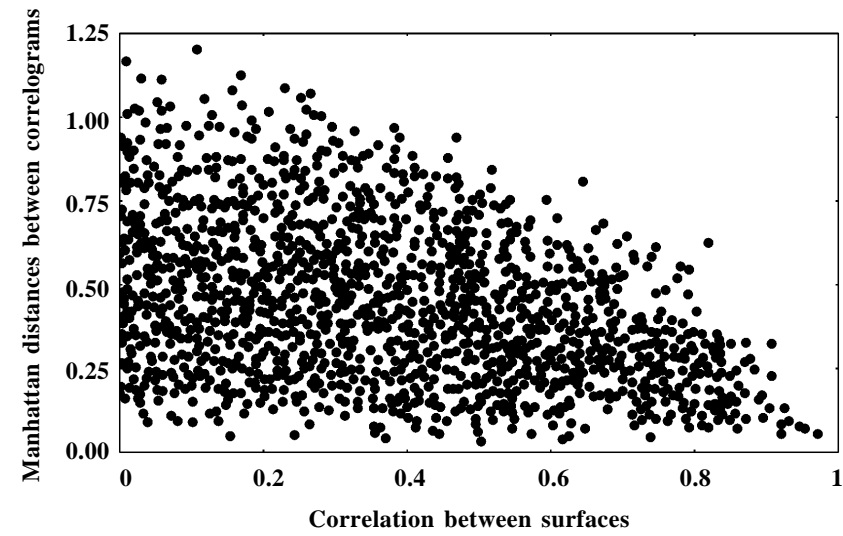

Figure 5 - Relationship between pairwise Manhattan distances between correlograms and correlations between gene frequency surfaces. Note that similar correlograms can be obtained from uncorrelated surfaces.

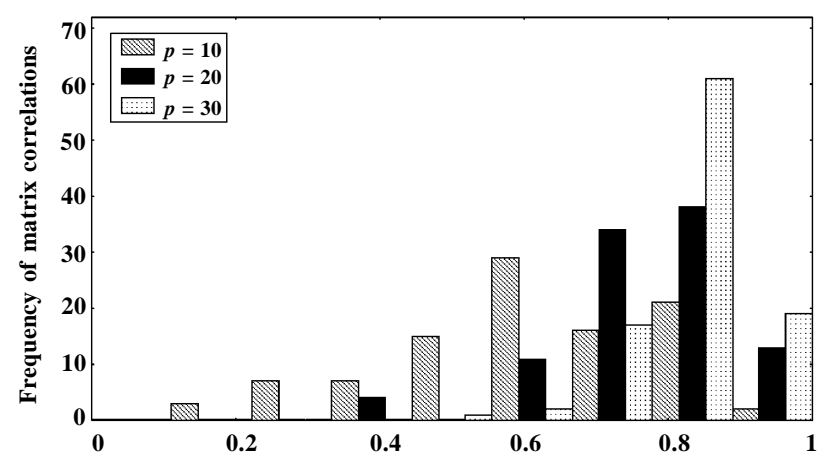

Matrix correlation (Nei's genetic distances versus geographic distances)

Figure 6 - Distribution of the matrix correlations (standardized Mantel tests) between Nei's (1972) genetic and geographic distances among populations. The genetic distances were calculated using increasing number of simulated $p$ gene frequencies.

terns. The profiles of the correlograms showed a decrease in Moran's I coefficient with increasing geographic distances, although the variance was low in the larger distance classes, as expected for an isolation-by-distance model and other stochastic models of genetic divergence among local populations in time and space (Sokal and Jacquez, 1991). Mantel tests used to evaluate the multivariate patterns of spatial autocorrelation in Nei's genetic distances supported these conclusions. Matrix correlation values, however, are sensitive to increases in the number of gene frequencies used to estimate genetic distances (see modal values of correlations in Figure 6).

The most important aspect revealed by the simulations was the wide range of variation in the correlograms obtained under the same stochastic process that mimics the isolation-by-distance model, which results in relatively high Manhattan distances among them. According to Sokal and Wartenberg (1983) and Sokal (1986), Manhattan dis- tances of 0.1-0.2 indicate the same spatial processes underlying the gene frequency surfaces, although it is difficult to make a final decision about a specific critical value. Indeed, our results show that this critical value is dependent on the sample size. With a relatively low number of local populations, as used in this study, more variation is expected in the profiles and, although the modal value of the Manhattan distance was very close to 0.2 , values up to 1.2 were obtained between correlograms generated by the same process.

The simulation strategy used in this study was completely different from that previously used to investigate microevolutionary processes using autocorrelation analyses (Sokal and Wartenberg, 1981; Sokal et al., 1989, 1997), despite the convergence of the results in terms of expectations of genetic divergence obtained with an isolation-bydistance model. Instead of simulating the dynamics of individuals in space across time and estimating the corresponding gene frequencies, we simply used a stochastic process that produced an exponential relationship between genetic divergence and geographic distance. This strategy, although less realistic, is more general because it does not explicitly use ecological and genetic parameters of the organisms (unknown for most species), and is based only on the shape of the relationship between divergence and space. Although biological parameters related to dispersion and drift obviously vary among different organisms, this relationship has been widely described by nonlinear equations. As such, null expectations would be generated using this procedure based only on information about the geographic coordinates of the local populations studied. This strategy is based on wellknown mathematical procedures that have been tested in phylogenetic comparative analyses and can be easily implemented using various computer programs (see Martins and Garland, 1991; Martins, 1996; Díaz-Uriarte and Garland, 1996). The correlograms and related statistics were similar to those previously found using these more realistic procedures, thus validating the simple approach proposed here.

The procedures adopted here do not allow one to test differences among correlograms generated by different microevolutionary processes, since they do not simulate such processes. The idea is simply to approximate the expected shape of the relationship between genetic divergence and geographic distance (which, in fact, would be generated by different combinations of microevolutionary processes). Nevertheless, this approach does permit one to establish a range of variation in correlogram profiles that could be obtained with a simple stochastic process that simulates the evolution of gene frequencies in isolationby-distance and related models. This possibility may be important when working with a few local populations because very distinct correlograms may be obtained by chance only. Such correlograms suggest that different microevolutionary processes are involved in gene frequency variation, but the approach used here indicated that they could be generated by a unique stochastic process. 
Computing the Manhattan distances among simulated correlograms allowed us to define a range for these values that would be expected in a specific situation (defined sample size and spatial distribution of local populations). If correlograms obtained with real genetic data for the same populations fall within this range, we may then conclude that autocorrelation analyses do not provide evidence that other microevolutionary processes, beyond simple stochastic variation structured across spatial dimension, are involved in gene frequency variation among local populations.

\section{ACKNOWLEDGMENTS}

The authors thank A.S.G. Coelho, F.A. Valva and L.J. Chaves for helpful discussions about population genetics and spatial structure. This work was partially supported by FUNAPE (Master's degree grant to M.P.C.T) and CNPq (research fellowship to J.A.F.D.F.).

\section{RESUMO}

Nesse artigo, um processo estocástico Ornstein-Uhlenbeck foi utilizado para simular a relação exponencial entre divergência genética e distância geográfica, conforme é esperado em modelos de isolamento-por-distância, alpondras ou coalescência. As simulações foram realizadas a partir de um dendrograma UPGMA estimado a partir das distâncias geográficas entre 13 populações locais. As superfícies espaciais de frequiências alélicas simuladas foram analisadas através de autocorrelação espacial e construção de distâncias genéticas de Nei, com base em diferentes números de alelos. A divergência entre populações locais produziu padrões espaciais significativos, tanto em nível univariado (correlogramas espaciais) quanto em nível multivariado (teste de Mantel entre distâncias de Nei e distâncias geográficas). Entretanto, se as análises são baseadas em um pequeno número de populações locais, os perfis dos correlogramas variam consideravelmente e as distâncias Manhattan calculadas entre eles podem ser maiores do que as previamente estabelecidas em outros estudos de simulação. O método proposto permite assim estabelecer uma amplitude de perfis que podem ser obtidos pelo mesmo processo estocástico de divergência genética. A comparação de correlogramas observados com esses perfis permite assim evitar o uso de outros mecanismos microevolutivos para explicar essa divergência genética.

\section{REFERENCES}

Avise, J.C. (2000). Phylogeography. Harvard University Press, Cambridge.

Barbujani, G. (1987). Autocorrelation of gene frequencies under isolationby-distance. Genetics 177: 772-782.

Díaz-Uriarte, R. and Garland, T. (1996). Testing hypotheses of correlated evolution using phylogenetically independent contrasts: sensitivity to deviations from Brownian motion. Syst. Biol. 45: 27-47.

Epperson, B.K. (1995a). Spatial distribution of genotypes under isolation by distance. Genetics 140: 1431-1440.

Epperson, B.K. (1995b). Spatial distribution of two-locus genotypes un- der isolation by distance. Genetics 140: 365-375.

Felsenstein, J. (1988). Phylogenies and quantitative characters. Аnnu. Rev. Ecol. Syst. 19: 445-471.

Hansen, T.F. and Martins, E.P. (1996). Translating between microevolutionary process and macroevolutionary patterns: the correlation structure of interspecific data. Evolution 50: 1404-1417.

Kimura, M. (1983). The Neutral Theory of Molecular Evolution. Cambridge University Press, Cambridge.

Kimura, M. and Weiss, G. (1964). The stepping stone model of population structure and the decrease of genetic correlation with distance. $\mathrm{Ge}$ netics 49: 561-576.

Manly, B.F.J. (1991). Randomization and Monte Carlo Methods in Biology. Chapman and Hall, London.

Martins, E.P. (1995). Phylogenies and comparative data: a microevolutionary perspective. Philos. Trans. R. Soc. Lond. B. 349: 85-91.

Martins, E.P. (1996). Phylogenies, spatial autoregression and the comparative method. Evolution 50: 1750-1765.

Martins, E.P. and Garland, T. (1991). Phylogenetic analyses of the correlated evolution of continuous characters: a simulation study. Evolution 45: 534-557.

Nei, M. (1972). Genetic distance between populations. Am. Nat. 106: 283 292.

Nielsen, R., Mountain, J.L., Huelsenbeck, J.P. and Slatkin, M. (1998) Maximum likelihood estimation of population divergence times and population phylogeny in models without mutation. Evolution 52: 669677.

Smouse, P.E., Long, J.C. and Sokal, R.R. (1986). Multiple regression and correlation extensions of the Mantel test of matrix correspondence. Syst. Zool. 35: 627-632.

Sneath, P.H.A. and Sokal, R.R. (1973). Numerical Taxonomy. W.H. Freeman, San Francisco.

Sokal, R.R. (1986). Spatial data analysis and historical processes. In: Data Analysis and Informatics IV (Diday et al., eds.). Science Publishers, Amsterdam, pp. 29-43.

Sokal, R.R. and Jacquez, G.M. (1991). Testing inferences about microevolutionary processes by means of spatial autocorrelation analysis. Evolution 45: 152-168.

Sokal, R.R. and Oden, N.L. (1978a). Spatial autocorrelation in biology. 1 Methodology. Biol. J. Linn. Soc. 10: 199-228.

Sokal, R.R. and Oden, N.L. (1978b). Spatial autocorrelation in biology. 2 Some biological implications and four applications of evolutionary and ecological interest. Biol. J. Linn. Soc. 10: 229-249.

Sokal, R.R. and Wartenberg, D. (1981). Space and population structure. In: Dynamic Spatial Models (Griffith, D. and McKinnon, R., eds.). Sijthoff and Noordhoff, Alohen ann den Rijn, Netherlands, pp. 186-213.

Sokal, R.R. and Wartenberg, D. (1983). A test of spatial autocorrelation using an isolation-by-distance model. Genetics 105: 219-237.

Sokal, R.R., Smouse, P.E. and Neel, J.V. (1986). The genetic structure of a tribal population, the Yanomama indians. XV. Patterns inferred by autocorrelation analysis. Genetics 114: 259-287.

Sokal, R.R., Jacquez, G.M. and Wooten, M.C. (1989). Spatial autocorrelation analysis of migration and selection. Genetics 121: 845-855.

Sokal, R.R., Oden, N.L. and Thomson, B.A. (1997). A simulation study of microevolutionary inferences by spatial autocorrelation analysis. Biol. J. Linn. Soc. 60: 73-93.

Telles, M.P.C. (2000). Diversidade genética e estrutura populacional de cagaiteira (Eugenia dysenterica DC.) no Sudeste de Goiás. Master's thesis, Universidade Federal de Goiás, Goiânia.

Wijsman, E.M. and Cavalli-Sforza, L.L. (1984). Migration and genetic population structure with special reference to humans. Annu. Rev. Ecol. Syst. 15: 279-301.

Wright, S. (1943). Isolation by distance. Genetics 28: 114-138.

(Received June 8, 2000) 
